\title{
Stigma in the context of schools: analysis of the phenomenon of stigma in a population of university students
}

\author{
Luca Pingani ${ }^{1,2^{*}}$, Sara Catellani ${ }^{1}$, Valeria Del Vecchio ${ }^{3}$, Gaia Sampogna ${ }^{3}$, Sarah E. Ellefson ${ }^{4}$, Marco Rigatelli ${ }^{5}$, \\ Andrea Fiorillo ${ }^{3}$, Sara Evans-Lacko ${ }^{6}$ and Patrick W. Corrigan ${ }^{4}$
}

\begin{abstract}
Background: Students have stereotyped views about people with mental illness. In particular, they believe that these persons are incurable, dangerous, unpredictable and responsible for their condition. This study aims to investigate the levels of public stigma in an Italian university population.

Methods: The Attribution Questionnaire 27 - Italian Version (AQ-27-I) was administered to a sample of students from the Faculty of Medicine and Surgery of the University of Modena and Reggio Emilia. After examining the psychometric characteristics of the AQ-27-I (Cronbach's Alpha and Confirmatory Factor Analysis), multiple linear regression analyses were carried out to identify the predictors of stigmatizing attitudes in this population.
\end{abstract}

Results: Three hundred and eleven students completed the questionnaire, with a response rate of $32.81 \%$ (out of the 948 contacted by email). The AQ-27-I showed good psychometric properties with an $a=.68$, and the fit indices of the models that partially supported the factor structure and paths. The two variables identified as possible predictors of stigmatizing attitudes (total score of AQ-27-I) were age and time spent reading newspapers.

Conclusions: Antistigma campaigns are needed in university contexts, targeted in particular to students in health professions.

Keywords: Mental health, Psychometrics, Reliability and validity, Stigma, Stereotypes, Questionnaires, University students

\section{Background}

Stigmatization is a social phenomenon leading to the marginalization of a specific member or a group of the community. Stigma leads to discrimination and loss of dignity as a result of prejudices by other members of the society [1]. Erving Goffman originally defined stigma as a mark or attribute that makes the person "from a whole and usual person to a tainted, discounted one" [2].

Six different types of stigma related to mental illness have been described in the literature: public stigma [3]; structural stigma [4]; self stigma [5]; felt or perceived stigma [6]; experienced stigma [6] and label avoidance $[7,8]$.

\footnotetext{
* Correspondence: luca.pingani@unimore.it

${ }^{1}$ Human Resource Development, Local Health Agency of Reggio Emilia, Via Amendola 2, Reggio Emilia, Italy

${ }^{2}$ International PhD School in Clinical and Experimental Medicine, University of Modena and Reggio Emilia, Via del Pozzo 71, Modena, Italy

Full list of author information is available at the end of the article
}

The stigmatized individual is assigned an attribute that makes him/her different and usually less desirable than others. The person is thus downgraded from being a full individual to a discredited person. As a result, the stigmatized person is isolated and marginalized. Stigma against persons with mental illness remains the strongest negative connotation of all social relations [9].

The attribution theory is an example of a social cognitive model that can be used to better understand stigma and in particular the belief that persons with mental illness are responsible for their mental health disorder ("public stigma"). Specifically, Weiner's attribution theory involves an interest in person's perceptions of causes of events [10]. Causal beliefs lead to assumptions regarding personal responsibility, which directly impacts a person's affect (usually in the form of anger or pity). These thoughts of personal responsibility and feelings regulate 
social behaviors toward the others [10]. If a person is perceived as responsible for his or her mental illness, then people may be angry towards the person, and will marginalize him or her through segregation and coercion. If the person is perceived as not responsible for his or her mental illness, then feelings of pity will emerge. A second concept of public stigma pertains to the notion that persons with mental illness are dangerous. Previously described as "danger appraisal", those who think that persons with mental illness are dangerous are more likely to react with fears and to avoid them [11, 12]. Discrimination against people with mental illness can result in negative social and health outcomes, such as difficulties in finding a job, discontinuation of studies, decrease in social network, reduced access to mental health care and low adherence to treatment.

Recent studies have reported that medical students believe that persons with mental illness are unpredictable, dangerous, and incurable [13]. Students in social work also endorse a desire to maintain social distance from people with mental illness [14]. Medical and nursing undergraduate students report not having enough information about mental disorders [15]. Previous studies have found that students' stigmatizing attitudes are influenced by socio-demographic characteristics, such as gender, age and culture, and by a direct or indirect experience of mental illness [13, 14, 16-20].

Over the last thirty years, several efforts have been made in Italy to improve the public understanding and acceptance of persons with mental disorders. In particular, in 1978 the "Basaglia law", which gradually closed psychiatric hospitals shifting mental health care in the community, should have increased the general public understanding and social contact with persons with serious mental illness [21, 22].

Another aspect we considered in our study is the knowledge of mental illness through newspapers and educational conferences on stigma. Mass media often portray persons with mental illness as dangerous and violent [23], and Italian newspapers often use psychiatric terms, such as schizophrenia, to describe incoherent, dangerous, aggressive, or odd behaviors [24, 25]. Thus, reading newspapers may result in an increase of stigma among the general population, as shown in a previous Italian multicenter study, which compared the opinions about mental illness of the general population, relatives and mental health professionals [26].

In this study, our primary aim was to validate the Italian version of the AQ 27 (AQ-27-I) in a medical student population. In secondary analyses, we assessed and verify possible predictors of stigmatization in the same population. To the best of our knowledge, no study has been carried out in Italy to explore the presence of stigmatizing attitudes in medical students.

\section{Methods \\ Sample}

All students $(N=948)$ attending a three-year first level degree course at the Faculty of Medicine and Surgery of the University of Modena and Reggio Emilia during the years 2011 and 2012 received an e-mail invitation to participate in the study, together with the study protocol. A sample of five times the number of questionnaire items is considered the minimum for confirmatory factor analysis: as the questionnaire is composed by 27 items, we needed a minimum of 135 completed questionnaires [27].

After providing informed consent, students who agreed to participate received an online version of the AQ-27-I with an ad-hoc schedule on their socio-demographic characteristics and three additional questions on the knowledge of Italian mental health care organization (i.e., knowledge of the thirtieth anniversary of the Basaglia law), previous educational experiences related to stigma (i.e., participation in scientific conferences) and exposure to information provided by mass media on mental health (i.e., time spent reading newspapers every day). The study obtained the ethical approval by the Board of Presidents of the Educational Courses of the Faculty of Medicine and Surgery of the University of Modena and Reggio Emilia (Italy).

\section{Instrument description}

The AQ-27-I is a 27-item self-administered questionnaire already validated in the Italian and Spanish languages for use with the general population [28, 29]. Respondents are asked to rate their level of agreement with each statement about "Harry", a 30-year-old single man with schizophrenia, on a Likert scale from 1 ("not at all") to 9 ("very much"). The AQ-27-I includes 9 subscales, each assessing a typical stereotype about people with mental illness: responsibility, pity, anger, dangerousness, fear, help, coercion, segregation and avoidance. Six items $(7,8,16,20,21$, 26) are reverse scored. Globally, the AQ-27-I provides a measure of public stigma. Higher scores indicate greater stigmatization toward Harry. The psychometric properties of the original questionnaire (AQ-27) were examined by two previous confirmatory factor analyses and found the AQ-27 to be acceptable and stable [1,30]. The AQ-27-I demonstrated an acceptable internal consistency, with a Cronbach's alpha of 0.82 for the total scale, and a satisfactory test-retest reliability, with intraclass correlation coefficient of 0.72 [28].

\section{Validation process}

Confirmatory factor analysis was performed to assess whether the original theoretical construct could be applied to a population of university students. Model fit was assessed using the following indices: $\chi 2$, Goodness of Fit Index (GFI $>0.90)$, Root Mean Square Error of 
Approximation (RMSEA $<0.05$ ), Adjusted Goodness of Fit Index (AGFI >0.90) and Comparative Fit Index (CFI > 0.90). Cronbach's alpha was used to assess instrument reliability $(\alpha \geq 0.65)$.

\section{Predictors of stigmatizing attitudes in the university population}

The relationship between stigma and (1) age, (2) sex, (3) knowledge of the "Basaglia law", (4) attendance of a conference on stigma, (5) time spent reading newspapers was explored using a multivariable linear regression for total score and every single subscales of AQ-27-I.

\section{Results}

Socio-demographic characteristics of the sample

A total of 311 (32.81\%) students signed the informed consent and returned the completed questionnaire. They are young (mean age: $22.78 \pm 3.80)$, and mostly female $(n=$ $217)$. Less than $50 \%(n=149)$ of respondents are aware of the thirtieth anniversary of the Basaglia law [18]; about $80 \%(n=248)$ never participated in seminars or conferences on stigma, and only $33 \%(n=102)$ usually read newspapers for about 20 min every day (Table 1 ).

Table 1 Socio-demographic characteristics of the sample $(n=311)$

\begin{tabular}{|c|c|c|}
\hline Variable & Frequency (n) & Percentage (\%) \\
\hline \multicolumn{3}{|l|}{ Gender } \\
\hline Male & 94 & 30.23 \\
\hline Female & 217 & 69.77 \\
\hline \multicolumn{3}{|l|}{ Civil status } \\
\hline Single & 143 & 45.98 \\
\hline Engaged & 160 & 51.45 \\
\hline Married & 7 & 2.25 \\
\hline Divorced & 1 & 0.32 \\
\hline \multicolumn{3}{|c|}{$\begin{array}{l}\text { Knowledge about celebration of the thirtieth anniversary of the } \\
\text { enactment of the Basaglia law? }\end{array}$} \\
\hline Yes & 149 & 47.91 \\
\hline No & 162 & 52.09 \\
\hline \multicolumn{3}{|c|}{$\begin{array}{l}\text { Participation in seminars or conferences related to the issue of stigma ir } \\
\text { psychiatry }\end{array}$} \\
\hline Yes & 63 & 20.26 \\
\hline No & 248 & 79.74 \\
\hline \multicolumn{3}{|c|}{ Daily time spent reading a newspaper (in minute) } \\
\hline 0 & 85 & 27.33 \\
\hline 10 & 82 & 26.37 \\
\hline 20 & 102 & 32.79 \\
\hline 30 & 28 & 9.00 \\
\hline 40 & 5 & 1.61 \\
\hline$>40$ & 9 & 2.89 \\
\hline
\end{tabular}

\section{Confirmatory factor analysis}

The path analysis of the attribution theory of personal responsibility for mental illness is shown in Fig. 1 [3]. The 18 items were defined as loading on six different first order latent factors [1, 30]: personal responsibility $(10,11,23)$, pity $(9,22,27)$, help $(8,20,21)$, anger $(1,4$, $12)$, coercion $(5,14,25)$ and segregation $(6,15,17)$. The path analysis indicates the significance of the chi square value $(\chi 2=308.53 ; \mathrm{df}=130 ; p<0.01)$ and a value for the $\chi 2$ /df ratio (2.37) above the reference value (2.0), which do not support fit. The GFI of 0.90 represents a good value, while both the AGFI $(=0.86)$ and the CFI $(=0.83)$ are slightly below the threshold. On the contrary, the value of the RMSEA $(=0.07)$ is slightly above the recommended values. The covariance estimate among factors is significant, with the exception of the associations of "personal responsibility" with "pity" $(-0.02 ; p=0.78)$, and of "anger" with "coercion" $(0.17 ; p=0.16)$. All the items loaded significantly into their corresponding factors.

On the basis of the results provided above, the personal responsibility model was divided into three sub-models (Fig. 2). The path analysis of sub-model A (personal responsibility $\rightarrow$ pity $\rightarrow$ help) resulted in a significant chi square $(\chi 2=66.18 ; \mathrm{df}=24 ; p<0.001)$ and a $\chi 2 / \mathrm{df}$ ratio $(2.76)$ above the reference value (2.0), not supporting the fit. The other three fit indices indicated an acceptable model fit (GFI = 0.95; AGFI $=0.91$; CFI $=0.91$; RMSEA $=0.08)$. The second path consisted of sub-model B (personal responsibility $\rightarrow$ anger $\rightarrow$ coercion), and the path analysis resulted in a significant chi square $(\chi 2=47.69 ; \mathrm{df}=24 ; p<0.005)$ and a $\chi 2 /$ df ratio (1.98) below the reference value (2.0), thus supporting the fit. Two of the four other fit indices indicated an acceptable model fit $(\mathrm{GFI}=0.97 ; \mathrm{AGFI}=0.94 ; \mathrm{CFI}=0.88$; RMSEA = 0.06). The third path consisted of sub-model $\mathrm{C}$ (personal responsibility $\rightarrow$ anger $\rightarrow$ segregation), and the path analysis resulted in a significant chi square $\left(\chi_{2}=\right.$ $185.63 ; \mathrm{df}=24 ; p<0.005)$ and a $\chi 2 / \mathrm{df}$ ratio (7.73) above the reference value (2.0), not supporting the fit. Only one of the four other fit indices indicated a good fit with the model $(\mathrm{GFI}=0.91$; AGF $=0.87$; CFI = 0.70; RMSEA = 0.09).

The pathway analysis related to the danger appraisal towards persons with mental disorders is shown in Fig. 3 [3]. Nine items loaded into three different first order latent factors: dangerousness (items 2,13,18), fear (items 3,19,24) and avoidance (items 7,16,26). The pathway analysis showed a significant chi square value $\left(\chi^{2}=61.96 ; \mathrm{df}=24 ; p<0.01\right)$ and a value for $\chi 2$ / $\mathrm{df}$ ratio (2.58) above the reference (2.0). The GFI $(=0.96)$, AGFI $(=0.93)$ and CFI $(=0.96)$ showed very good values, while $\mathrm{RMSEA}=0.07$ was slightly above the recommended values. All items loaded significantly into the corresponding factors and the estimated covariance between factors was always significant, ranging from -1.16 to 1.04 . 


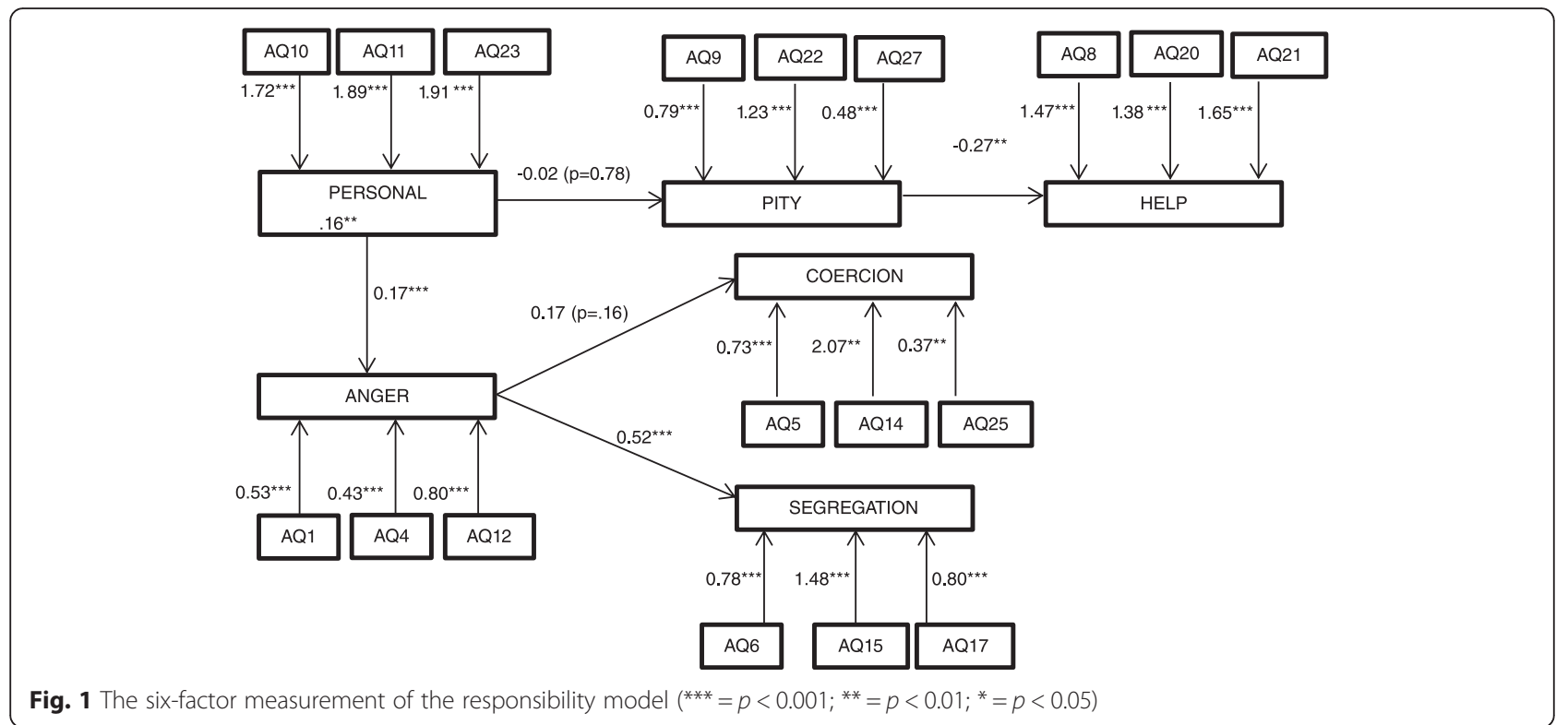

\section{Internal consistency reliability}

Cronbach's alpha, used to test internal consistency, was 0.68. The "Fear" subscale showed the highest value of Internal Consistency Reliability (0.83). Two other subscales ("Pity" $=0.63$ and "Dangerousness" $=0.60$ ) achieved a score slightly below the cut-off, while the "Responsibility" subscale obtained a very low value $(0.48)$ (Table 2$)$.

\section{Analysis of dependence of AQ-27-I scores}

Multiple linear regression analysis was used to develop a model for predicting the total score of the AQ-27-I and the score of the subscales using five independent variables (age, sex, time spent reading newspapers, knowledge of the Basaglia law and participation in conferences on stigma) (Table 3). Two subscales (responsibility and anger) did not show any association with the independent variables. The subscale avoidance was negatively associated with the independent variables "knowledge of the Basaglia law" ( $\beta=-0.18 ; p=0.002)$ and "participation at conferences on stigma" $(\beta=-0.13 ; p=0.02)$. The independent variable "age" was negatively associated with four subscales of the AQ-27-I: coercion $(\beta=-0.12 ; p=0.04)$, segregation $(\beta=-0.33 ; p=0.001)$, fear $(\beta=-0.12 ; p=$ $0.03)$ and avoidance $(\beta=-0.11 ; p=0.05)$. Two positive associations were found between the variable "time spent in reading newspapers daily" and the subscales segregation $(\beta=0.12 ; p=0.03)$ and dangerousness $(\beta=$ $0.11 ; p=0.04)$. The independent variable "sex" was also related to the help $(\beta=0.16 ; p=0.004)$ and dangerousness $(\beta=-0.12 ; p=0.04)$ subscales. Finally, the "Pity" subscale was associated with the variable "knowledge of the Basaglia law" $(\beta=-0.12 ; p=0.03)$. Using the total score of AQ-27-I as dependent variable only two hypothetic predictors were found: age $(\beta=-0.12 ; p=0.04)$ and time spent in reading newspapers $(\beta=0.17 ; p=0.04)$

\section{Discussion}

The primary aim of the study was to validate the AQ27-I in a medical student population. The confirmatory factor analysis of the model of personal responsibility scored slightly below the reference ranges (with the exception of the GFI, which was 0.90). The results of the path analysis were only partially overlapping with the previous validation: in particular, we did not find a

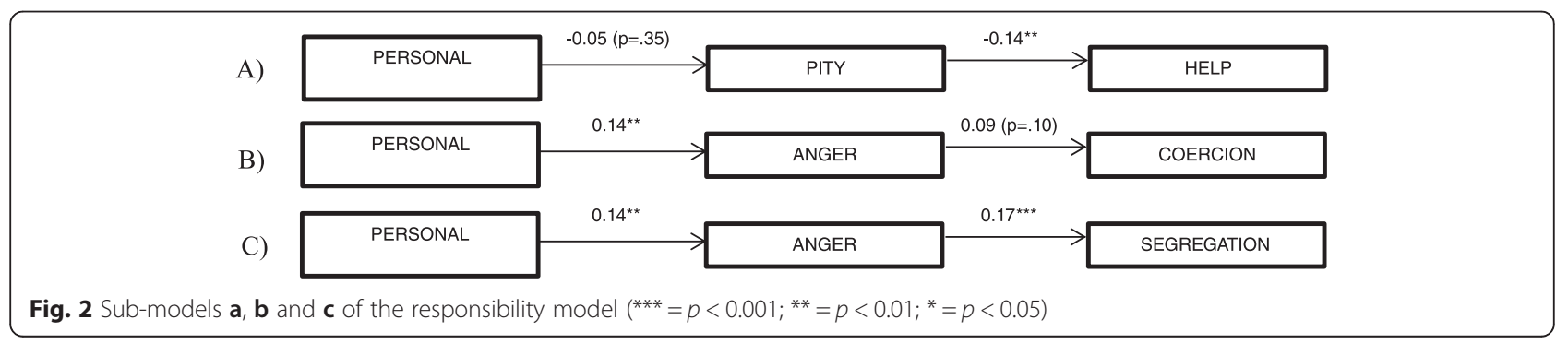




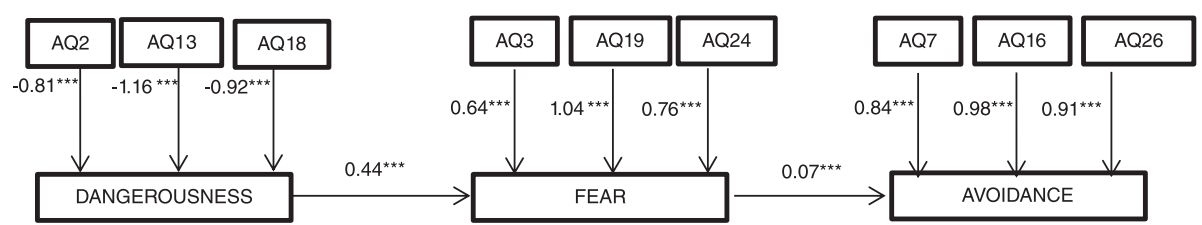

Fig. 3 The three-factor measurement of the dangerousness model $\left({ }^{* *}=p<0.001 ;{ }^{* *}=p<0.01 ;{ }^{*}=p<0.05\right)$

significant association between anger and coercion, and between pity and help, and the $\chi 2 / \mathrm{df}$ ratio did not support the fit. The behavioral response of segregation may be considered more appropriate to the emotional state of anger due to the fact that the individual with mental illness is considered responsible for his problems [31-34].

The results obtained from the second model ("Danger Appraisal model") are more robust, but again the $x 2 / \mathrm{df}$ ratio does not support the fit. All covariances between the various factors of the model have reached a statistical significance ("dangerousness" with "fear" and "fear" with "avoidance"). Additionally, all the nine items loaded in their respective three factors. With regard to the fit indices, the results were satisfactory: only the RMSEA was above the cut-off, while all other indicators (GFI, AGFI and CFI) were within the cut-off. Therefore, the danger appraisal model seems to be a better fit with the Italian cultural context and it is more applicable in medical students. The internal consistency reliability of the questionnaire is 0.68 . Three factors (dangerousness, fear and coercion) were below the threshold. This result suggests that other confounding variables could play an important role in the remaining variance.

The second aim of this study was to define possible predictors of stigmatizing attitudes in a medical student population. The analysis of associations between the subscales and the total score of AQ-27-I with the other collected

Table 2 Internal consistency (Cronbach's alpha coefficient)

\begin{tabular}{ll}
\hline AQ-27-I & $\begin{array}{l}\text { Internal consistency reliability (Cronbach's alpha } \\
\text { coefficient) }\end{array}$ \\
\hline Responsibility & 0.48 \\
Pity & 0.63 \\
Anger & 0.74 \\
Dangerousness & 0.60 \\
Fear & 0.83 \\
Help & 0.77 \\
Coercion & 0.63 \\
Segregation & 0.82 \\
Avoidance & 0.71 \\
Total & 0.68 \\
\hline
\end{tabular}

variables for defining possible stigmatizing attitudes in a university student population has allowed us to confirm data already available in the literature. In particular, our results show that being female is associated with a lower score on the dangerousness subscale and a higher score on the help subscale, thus confirming that negative prejudices against people with psychiatric disorders are higher in males [35].

Another interesting finding is the inversely proportional association between age as independent variable and the subscales coercion, segregation and dangerousness: the subscales' scores decrease as age increases. We can assume that during their degree course, students address issues related to ethics, deontology and the relationship between health professionals and patients, thus reducing their stigmatizing behaviors and stereotypes.

One of the main sources of stigma is how people with mental disorders are portrayed in newspapers: unreliable, insecure and dangerous [36, 37]. In our study, this hypothesis is strengthened by the direct relationship between time spent in reading newspapers and the sense of danger, with the consequent desire of segregation, caused by people with psychiatric disorders.

The attendance in events on stigma is associated with less avoidance. However, from the evidence available in the literature [38] about the effectiveness of educational interventions as a mean to fight stigma, this finding requires more confirmation and it has to be considered speculative.

Finally, it is interesting to note that the knowledge of the thirtieth anniversary of the Basaglia law is associated with lower levels of stigmatizing attitudes (i.e., low scores on the pity and avoidance subscales) [39]. Although this association can be by chance, it is likely that the principles of the Italian law have been well received by the population, and that patients with mental disorders are not avoided.

\section{Conclusions}

This cross-sectional study has some limitations, which have to be considered. The main limitation is that unfortunately we did not consider the strongest predictor of positive attitudes, which is knowing someone with a mental health problem (social contact) $[17,40]$. Second, 
Table 3 Multiple linear regression between the subscale and the total score of the AQ-27-I (dependent variables) and the other independent variables

\begin{tabular}{llllll}
\hline & Age & Sex & $\begin{array}{l}\text { Knowledge of } \\
\text { Basaglia law }\end{array}$ & $\begin{array}{l}\text { Conferences related } \\
\text { to stigma }\end{array}$ & $\begin{array}{l}\text { Daily time spent reading } \\
\text { a newspaper }\end{array}$ \\
\hline Responsibility & $\beta=0.03 ; p=0.64$ & $\beta=-0.05 ; p=0.38$ & $\beta=-0.05 ; p=0.38$ & $\beta=0.04 ; p=0.49$ & $\beta=0.11 ; p=0.06$ \\
Pity & $\beta=-0.01 ; p=0.83$ & $\beta=-0.10 ; p=0.07$ & $\beta=-0.12 ; p=0.03$ & $\beta=-0.01 ; p=0.88$ & $\beta=-0.02 ; p=0.79$ \\
Help & $\beta=-0.04 ; p=0.46$ & $\beta=0.16 ; p=0.004$ & $\beta=0.09 ; p=0.11$ & $\beta=0.07 ; p=0.21$ & $\beta=0.10 ; p=0.09$ \\
Anger & $\beta=0.001 ; p=0.98$ & $\beta=-0.10 ; p=0.07$ & $\beta=0.03 ; p=0.56$ & $\beta=0.04 ; p=0.51$ & $\beta=0.11 ; p=0.06$ \\
Coercion & $\beta=-0.12 ; p=0.04$ & $\beta=0.04 ; p=0.40$ & $\beta=0.04 ; p=0.56$ & $\beta=0.10 ; p=0.08$ & $\beta=0.01 ; p=0.79$ \\
Segregation & $\beta=-0.33 ; p=0.001$ & $\beta=-0.08 ; p=0.16$ & $\beta=-0.11 ; p=0.06$ & $\beta=-0.09 ; p=0.10$ & $\beta=0.12 ; p=0.03$ \\
Dangerousness & $\beta=-0.003 ; p=0.96$ & $\beta=-0.12 ; p=0.04$ & $\beta=0.06 ; p=0.92$ & $\beta=0.02 ; p=0.69$ & $\beta=0.11 ; p=0.04$ \\
Fear & $\beta=-0.12 ; p=0.03$ & $\beta=0.04 ; p=0.49$ & $\beta=-0.07 ; p=0.23$ & $\beta=-0.02 ; p=0.66$ & $\beta=0.07 ; p=0.20$ \\
Avoidance & $\beta=-0.11 ; p=0.05$ & $\beta=-0.08 ; p=0.16$ & $\beta=-0.18 ; p=0.002$ & $\beta=-0.13 ; p=0.02$ & $\beta=-0.08 ; p=0.16$ \\
Total Score & $\beta=-0.12 ; p=0.04$ & $\beta=-0.05 ; p=0.45$ & $\beta=-0.08 ; p=0.32$ & $\beta=0.07 ; p=0.30$ & $\beta=0.17 ; p=0.04$ \\
\hline
\end{tabular}

the sample included medical students who have agreed to participate in the survey because of their interest in the topic, and we do not have information on students who did not agree to participate. Third, participants were recruited at the Faculty of Medicine, and it may be that these students are more sensitive on social issues. Further studies should explore this phenomenon in students from other areas of knowledge. Fourth, we had a quite low response rate $(32.8 \% ; 311 / 948)$, which may be due to lack of time to fill in the questionnaire or to have not received the invitation by e-mail. Although the sample size was sufficient enough to carry out the study and to perform statistical analyses, we acknowledge that the response rate might have biased the results, since those who responded may be more interested in the topic.

The analysis of possible characteristics associated with AQ-27-I subscales represents a first step for explaining the dynamics of stigma among university students: however, in order to have a clearer picture of this phenomenon, it is necessary to proceed with the definition of more complex models. Our findings confirm the need to improve strategies to fight stigma in university contexts. In particular, it may be relevant to include different teaching activities, such as seminars, first-person accounts and educational materials on stigma, or to involve mass media [41]. With these activities, we could verify which strategy (educational or contact) is most effective for reducing stigma and discrimination in school populations.

\section{Competing interests}

The authors declare that they have no competing interests.

\section{Authors' contributions}

LP developed the study protocol, performed statistical analyses, wrote and finalized the draft. SEL, MR, AF and PWC contributed to study conception, design, and interpretation of findings. SC, VDV and SE collected the data and contributed to interpretation of data. GS contributed to data collection, revised the paper and contributed to statistical analyses. All authors read and approved the final version of the manuscript.

\section{Acknowledgements}

This research received no specific grant from any funding agency, commercial or not-for-profit sectors. We are grateful to all respondents for giving us their time. They made this study possible.

\section{Author details}

${ }^{1}$ Human Resource Development, Local Health Agency of Reggio Emilia, Via Amendola 2, Reggio Emilia, Italy. ${ }^{2}$ International PhD School in Clinical and Experimental Medicine, University of Modena and Reggio Emilia, Via del Pozzo 71, Modena, Italy. ${ }^{3}$ Department of Psychiatry, University of Naples SUN, Largo Madonna delle Grazie, Naples, Italy. ${ }^{4}$ Institute of Psychology, Illinois Institute of Technology, 3424 S. State Street, Chicago, USA. ${ }^{5}$ Department of Diagnostic Medicine, Clinical and Public Health, University of Modena and Reggio Emilia, Via del Pozzo 71, Modena, Italy. 'Institute of Psychiatry, Psychology \& Neuroscience, King's College London, De Crespigny Park, London SE58AF, UK

Received: 7 October 2014 Accepted: 3 February 2016

Published online: 09 February 2016

\section{References}

1. Corrigan P, Markowitz F, Watson A, Rowan D, Kubiak M. An attribution model of public discrimination towards persons with mental illness. J Health Soc Behav. 2003;44(2):162-79.

2. Goffman E. Stigma: Notes on the Management of Spoiled Identity. New York: Simon and Schuster; 1963.

3. Corrigan PW, Watson AC. Understanding the impact of stigma on people with mental illness. World Psychiatry. 2002;1(1):16-20.

4. Corrigan PW, Watson AC, Heyrman ML, Warpinski A, Gracia G, Slopen N, et al. Structural stigma in state legislation. Psychiatr Serv. 2005;56(5):557-63.

5. Watson AC, Corrigan P, Larson JE, Sells M. Self-stigma in people with mental illness. Schizophr Bull. 2007:33(6):1312-8.

6. Van Brakel W. Measuring health-related stigma-a literature review. Psychol Health Med. 2006;11(3):307-34.

7. Clement S, Schauman O, Graham T, Maggioni F, Evans-Lacko S, Bezborodovs $\mathrm{N}$, et al. What is the impact of mental health-related stigma on help-seeking? A systematic review of quantitative and qualitative studies. Psychol Med. 2015;45(1):11-27.

8. Ben-Zeev D, Young MA, Corrigan PW. DSM-V and the stigma of mental illness. J Ment Health. 2010;19(4):318-27.

9. Byrne P. Stigma of mental illness and ways of diminishing it. Adv Psychiatr Treat. 2000;6:65-72.

10. Weiner B. Judgments of responsibility: A foundation for a theory of social conduct. New York: Guilford; 1995. 
11. Edwards J, Endler N. Appraisal of stressful situations. Personal Individ Differ 1989;10:7-10.

12. Paterson RJ, Neufeld RW. Clear danger: situational determinants of the appraisal of threat. Psychol Bull. 1987;101(3):404-16.

13. Schenner M, Kohlbauer D, Günther V. Communicate instead of stigmatizing - does social contact with a depressed person change attitudes of medical students towards psychiatric disorders? A study of attitudes of medical students to psychiatric patients. Neuropsychiatr. 2011;25(4):199-207.

14. Covarrubias I, Han M. Mental health stigma about serious mental illness among MSW students: social contact and attitude. Soc Work. 2011;56(4): 317-25.

15. Llerena A, Cáceres MC, Peñas-LLedó EM. Schizophrenia stigma among medical and nursing undergraduates. Eur Psychiatry. 2002;17(5):298-9.

16. Korszun A, Dinos S, Ahmed K, Bhui K. Medical student attitudes about mental illness: does medical-school education reduce stigma? Acad Psychiatry. 2012;36(3):197-204.

17. Corrigan PW, Morris SB, Michaels PJ, Rafacz JD, Rüsch N. Challenging the public stigma of mental illness: a meta-analysis of outcome studies. Psychiatr Serv. 2012;63(10):963-73.

18. Pingani L, Fiorillo A, Luciano M, Catellani S, Vinci V, Ferrari S, et al. Who cares for it? How to provide psychosocial interventions in the community. Int J Soc Psychiatry. 2012.

19. Roberts L, Wiskin C, Roalfe A. Effects of exposure to mental illness in roleplay on undergraduate student attitudes. Medical School Education. 2008; 40:477-83.

20. Neumann E, Obliers R, Albus C. Medical students' attitudes towards mental illness: a matter of studies or personality? Psychother Psychosom Med Psychol. 2012;62:66-72.

21. Barbato A. Psychiatry in transition: outcomes of mental health policy shift in Italy. Aust N Z J Psychiatry. 1998;32(5):673-9.

22. de Girolamo G, Cozza M. The Italian Psychiatric Reform. A 20-year perspective. Int J Law Psychiatry. 2000;23(3-4):197-214.

23. Corrigan P, Watson A, Gracia G, Slopen N, Rasinski K, Hall L. Newspaper stories as measures of structural stigma. Psychiat Serv. 2005:56:551-6.

24. Magliano L, Read J, Marassi R. Metaphoric and non-metaphoric use of the term "schizophrenia" in Italian newspapers. Soc Psych Psych Epid. 2011;46: 1019-25.

25. Pingani L, Evans-Lacko S, Del Vecchio V, Luciano M, Catellani S, Hamati A, et al. University students' identification of stigmatizing schizophrenia in Italian newspapers. Am J Orthopsychiatry. 2015;85(2):139-44.

26. Magliano L, Fiorillo A, De Rosa C, Malangone C, Maj M. Beliefs about schizophrenia in Italy: a comparative nationwide survey of the general public, mental health professionals, and patients' relatives. Can J Psychiatry. 2004:49(5):322-30.

27. Hair M, Anderson R, Tatham R, Black W. Multivariate data analysis. New Jersey: Prentice Hall; 1998.

28. Pingani L, Forghieri M, Ferrari S, Ben-Zeev D, Artoni P, Mazzi F, et al. Stigma and discrimination toward mental illness: translation and validation of the Italian version of the Attribution Questionnaire-27 (AQ-27-I). Soc Psychiatry Psychiatr Epidemiol. 2012;47(6):993-9.

29. Muñoz M, Guillén A, Pérez-Santos E, Corrigan PW. A structural equation modeling study of the Spanish Mental Illness Stigma Attribution Questionnaire (AQ-27-E). Am J Orthopsychiatry. 2015;85(3):243-9.

30. Corrigan P, Rowan D, Green A, Lundin R, River P, Uphoff-Wasowski K, et al. Challenging two mental illness stigmas: personal responsibility and dangerousness. Schizophr Bull. 2002;28(2):293-309.

31. Ashcraft L, Bloss M, Anthony WA. Best practices: The development and implementation of "no force first" as a best practice. Psychiatr Serv. 2012; 63(5):415-7.

32. Arya D. Compulsory treatment and patient responsibility. Australas Psychiatry. 2012;20(6):472-7.

33. Fiorillo A, De Rosa C, Del Vecchio V, Jurjanz L, Schnall K, Onchev G, et al. How to improve clinical practice on involuntary hospital admissions of psychiatric patients: suggestions from the EUNOMIA study. Eur Psychiatry. 2011;26(4):201-7

34. Fiorillo A, Giacco D, De Rosa C, Kallert T, Katsakou C, Onchev G, et al. Patient characteristics and symptoms associated with perceived coercion during hospital treatment. Acta Psychiatr Scand. 2012;125(6):460-7.

35. Angermeyer MC, Matschinger $\mathrm{H}$, Holzinger A. Gender and attitudes towards people with schizophrenia. Results of a representative survey in the Federal Republic of Germany. Int J Soc Psychiatry. 1998;44(2):107-16.
36. Vahabzadeh A, Wittenauer J, Carr E. Stigma, schizophrenia and the media: exploring changes in the reporting of schizophrenia in major U.S newspapers. J Psychiatr Pract. 2011;17(6):439-46.

37. Carpiniello B, Girau R, Orrù MG. Mass-media, violence and mental illness. Evidence from some Italian newspapers. Epidemiol Psichiatr Soc. 2007;16(3): 251-5.

38. Fiorillo A, Bassi M, De Girolamo G, Catapano F, Romeo F. The impact of a psychoeducational intervention on family members' views about schizophrenia: results from the OASIS Italian multi-centre study. Int I Soc Psychiatry. 2011;57:596-603.

39. De Girolamo G, Barale F, Politi P, Fusar-Poli P. Franco Basaglia, 1924-1980. Am J Psychiatry. 2008;165:968.

40. London J, Evans-Lacko SE. Challenging mental health-related stigma through social contact. Eur J Public Health. 2010;20(2):130-1.

41. Clement S, Lassman F, Barley E, Evans-Lacko S, Williams P, Yamaguchi S, et al. Mass media interventions for reducing mental health-related stigma. Cochrane Database Syst Rev. 2013;7:CD009453.23.

\section{Submit your next manuscript to BioMed Central and we will help you at every step:}

- We accept pre-submission inquiries

- Our selector tool helps you to find the most relevant journal

- We provide round the clock customer support

- Convenient online submission

- Thorough peer review

- Inclusion in PubMed and all major indexing services

- Maximum visibility for your research

Submit your manuscript at www.biomedcentral.com/submit
) Biomed Central 